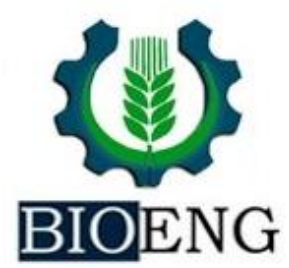

\title{
DESENVOLVIMENTO DE UMA SMART HOUSE NO CURSO DE ENGENHARIA DE BIOSSISTEMAS
}

\author{
M. Matulovic ${ }^{1 *}$, M. Mollo Neto ${ }^{1}$, B. Hiromoto ${ }^{1}$, L. Eivazian ${ }^{1}$, M. L. \\ Ribeiro $^{1}$
}

\author{
${ }^{1}$ São Paulo State University (UNESP), School of Science and Engineering, Tupã, Postal Code \\ 17602-496, Tupã, SP, Brazil.
}

Article history: Received 06 March 2020; Received in revised form 10 March 2020; Accepted 17 March 2020; Available online 31 March 2020.

\section{RESUMO}

Tecnologias da Indústria 4.0 estão trazendo novas oportunidades, desafios e soluções para muitos domínios, incluindo agricultura, ciências das plantas, ciências animais, ciências dos alimentos e ciências sociais. Neste cenário, não apenas as empresas industriais têm de aprender tecnologias relevantes, mas também o meio acadêmico está interessado em mudanças no currículo educacional para incluir e refletir sobre as novas tecnologias, conceitos e paradigmas. A inclusão da impressão 3D nos currículos escolares também é positiva sob outra perspectiva pedagógica, pois pode oferecer oportunidades para diferentes estilos de aprendizagem a serem praticados. Esta pesquisa objetiva analisar o trabalho em que discentes tutorados por docentes do curso de Engenharia desenvolveram em termos de planejamento, construção, instrumentação e elaboração de um sistema supervisório de uma "Smart House", de forma a fundamentar o aprendizado por meio da construção de uma maquete utilizando técnicas de impressão 3D e instrumentação, fixando assim os conceitos de IoT, automação, supervisão e controle, uso de sensores e atuadores, programação de CLPs e o desenvolvimento de aplicativos de supervisão e controle remoto de utilidades. Os resultados apontaram para o fato de que tratar o tema de modo inter e transdisciplinar mostrou-se uma necessidade nos cursos de Engenharia das Universidades, principalmente naquelas em que os objetivos maiores residem na utilização de tecnologias em suas práticas de trabalho. A pesquisa e o experimentos proposto proporcionaram aos discentes a agregação de valor no processo de aprendizagem ocasionando a transcendência dos conhecimentos interdisciplinares inerentes ao próprio curso.

Palavras-Chave: Educação 4.0, Sensoriamento, Supervisão e Controle, Prototipagem 3D.

\section{DEVELOPMENT OF A SMART HOUSE IN THE BIOSYSTEM ENGINEERING COURSE}

\begin{abstract}
Technologies of Industry 4.0 are bringing new opportunities, challenges and solutions to many domains, including agriculture, plant sciences, animal sciences, food sciences and social sciences. In this scenario, not only industrial companies have to learn relevant technologies, but also the academic environment is interested in changes in the educational curriculum to include and reflect on new technologies, concepts and paradigms. The inclusion
\end{abstract}

*mariana.matulovic@unesp.br 
of 3D printing in school curricula is also positive from another pedagogical perspective, as it can offer opportunities for different learning styles to be practiced. Thus, this research aims to evaluate the work in which students tutored by professors of the Engineering course, develop the planning, construction, instrumentation and elaboration of a supervisory system of a "Smart House", in order to base the learning through the construction of a model using 3D printing techniques and instrumentation, thus fixing the concepts of IoT, automation, supervision and control, use of sensors and actuators, PLC programming and the development of supervision and remote control utility applications. The results pointed to the fact that dealing with the theme in an inter and transdisciplinary way proved to be a necessity in Engineering courses at Universities, especially those in which the main objectives lie in the use of technologies in their work and research practices and the experiment. The proposed method provided students with added value in the learning process that ended up transcending the interdisciplinary knowledge inherent in the course itself.

Keywords: Education 4.0, Sensing, Supervision and Control, 3D Prototyping.

\section{INTRODUÇÃO}

Tecnologias emergentes como Internet das Coisas, Ciência de Dados, Aprendizado Profundo, Realidade Aumentada, Edge Computing e Digital Twins estão trazendo novas oportunidades, desafios e soluções para muitos domínios, incluindo agricultura, ciências das plantas, ciências animais, ciências dos alimentos e ciências sociais (CATAL E TEKINERDOGAN, 2019).

Devido aos enormes benefícios da Indústria 4.0 e ao conhecimento, tecnologias e experiência necessários para a implementação e gerenciamento desses sistemas, ainda segundo Catal e Tekinerdogan (2019), não apenas as empresas industriais têm grande ambição de aprender tecnologias relevantes, mas também o meio acadêmico está interessado em mudanças no currículo educacional para incluir e refletir sobre as novas tecnologias, novos conceitos e paradigmas.

Segundo descrevem em sua pesquisa, Sung e Hsiau (2020), muitos estudos se concentraram nas casas inteligentes ou "Smart Houses" com a ideia de compartilhamento de espaços confortáveis e seguros.

Os mesmos autores dizem que, em particular, com as melhorias de valor técnico, compatibilidade de domínio, compartilhamento de tecnologia e inovação em P\&D nos últimos anos, as pesquisas relacionadas à "Smart House" foram mais extensas e abrangem uma ampla gama de áreas, como avaliação ambiental, melhoria de transmissão e até aprimoramento do projeto arquitetônico.

O termo "Smart House" remete a uma concepção de casa que possui sistemas avançados de automação para promover soluções que facilitam a vida do ser humano, tais como controle de temperatura e umidade em áreas internas e externas da residência para acionamento de ar condicionado e sistemas de irrigação, portões automáticos, multimídia conectada com dispositivos de celulares, alarmes monitorados por celulares, dentre outros.

Esta concepção de ambientes equipados com sensores e redes de comunicações é uma aplicação direta dos conceitos que norteiam a indústria 4.0, imagináveis apenas em filmes de ficção científica nos anos 80, e atualmente, uma realidade (GHAFFARIANHOSEINI et al., 2013).

O principal conceito da IoT (Internet of Things) é "a integração da virtualidade e da realidade e a interconexão de todas as coisas", que também podem ser entendidas como o fenômeno de que todas as coisas no mundo, sejam "seres humanos", "coisas", "tempo", "locais" ou "objetos", 
podem ser interconectados pela Internet (LI e NABRZYSKI, 2018).

As 3 primeiras revoluções industriais promoveram a ideia da massificação da produção, linhas de montagem, eletrônica e o desenvolvimento de uma automação de, relativamente baixo custo, mas pouca acessibilidade (MARQUES (a), 2017).

Já a quarta revolução industrial, ocorreu impactante e progressivamente, em razão de se caracterizar como um conjunto de tecnologias que integram domínios aparentemente desconectados, tais como a Manufatura Aditiva, Sensoriamento, Big Data, Machine Learning, IoT e sistemas Cyber-físicos (MARQUES (b), 2017).

$O$ surgimento de tecnologias de fabricação aditiva e impressão 3D está introduzindo a potencialização de habilidades industriais e oportunidades para novas práticas de ensino em uma variedade de assuntos e ambientes educacionais (FORD e MINSHALLA, 2019).

A inclusão da impressão 3D nos currículos escolares também é positiva sob outra perspectiva pedagógica, pois pode oferecer oportunidades para diferentes estilos de aprendizagem a serem praticados, incluindo aprendizado experimental e fracasso (BLIKSTEIN, 2013).

Segundo as pesquisas de Ford e Minshalla (2019), no ensino superior, a adoção da impressão 3D é maior nas universidades e há relativamente poucos relatórios sobre a utilização da tecnologia em outras instituições de educação básica e superior.

\section{MATERIAL E MÉTODOS}

A graduação de Engenharia de Biossistemas, da Universidade Estadual Paulista (UNESP), Campus de Tupã/SP, tem como um de seus pilares agregar tecnologias 4.0 aos sistemas biológicos com vistas a desenvolvimentos sustentáveis no uso da terra, do meio ambiente, da agricultura e da indústria.
Os mesmos autores reforçam que nos artigos que relatam o uso da impressão 3D nas universidades, é possível encontrar literatura que descreve a aquisição de conhecimentos sobre o assunto através da criação de sistemas de impressão 3D, modelos científicos e modelos de teste; o uso da impressão 3D durante o aprendizado baseado em projetos; a integração do desenvolvimento de habilidades da impressão 3D no currículo por meio da incorporação em cursos existentes e da introdução de novos cursos; e envolvimento externo.

Neste contexto, este artigo centra-se nos objetivos de que discentes tutorados por docentes do curso de Engenharia de Biossistemas da Faculdade de Ciências e Engenharia (FCE) da Universidade Estadual Paulista "Júlio de Mesquita Filho" - Unesp Câmpus de Tupã/SP, possam desenvolver o planejamento, a construção, o sensoriamento e elaboração de um sistema supervisório de uma "Smart House".

Este trabalho tutorado agregará valor ao processo de formação de maneira a desenvolver o aprendizado discente por meio da construção de uma maquete utilizando técnicas de impressão 3D e instrumentando a mesma, fixando os conceitos de IoT, automação, supervisão e controle, uso de sensores e atuadores, programação de CLPs e o desenvolvimento de aplicativos de supervisão e controle remoto de modo a criar um modelo, ou protótipo, de uma construção inteligente nos moldes de uma "Smart House".

Neste cenário, discentes do curso, tutorados pelos docentes, projetaram e desenvolveram um protótipo, de baixo custo, de uma casa inteligente e realizaram sua instrumentação e sistema supervisório.

Para tanto, foram utilizados os seguintes materiais: 
1) Relé Programável e $I / O$ remoto da marca HI Tecnologia, modelo Rion (HIO115), alimentado com 10 a 30 Vcc, com 8 entradas digitais, 4 saídas digitais, 3 entradas analógicas, com 1 encoder, 2 contadores rápidos e 1 PWM, comunicação por cabo Ethernet ou serial.

2) Sensores fotoelétricos E3F- DS30P1, com detecção difusa, PNP, normalmente aberto, tensão de funcionamento de 10 a 30 Vcc, corrente de saída de 300mA, distância mínima de atuação de $2 \mathrm{~mm}$ e distância sensorial máxima de 10 a $30 \mathrm{~cm}$. Este sensor foi utilizado para realizar a abertura da porta principal da casa.

3) Sensor de temperatura e umidade (THT860) com uma saida analógica 4.a.20 mA, uma entrada digital para seleção de grandeza, para irrigar o jardim quando necessário.

4) Micro ventilador Cooler 120x120x28mm, para o resfriamento do ambiente.

5) Motor elétrico da marca MABUCHI de $12 \mathrm{Vcc}$, com pinhão de 8 dentes.

6) Sensor de temperatura LM35.

\section{RESULTADOS E DISCUSSÃO}

\subsection{O projeto e Construção da Maquete}

O projeto da maquete da "Smart House" em 3D, segundo indicam Sung e Hsiau (2020) e Blikstein (2013), foi elaborado no software Inventor Professional 2017, da Autodesk, Build 142.

Inicialmente, projetaram-se as peças do maquinário separadamente, e, após a visualização do conjunto, montou-
Além destes materiais, foi utilizado um computador com os seguintes softwares instalados e este foi também conectado a uma impressora 3D:

1) Software Inventor Professional 2017, da Autodesk, Build 142.

2) Software SPDSW 4.4.

3) Software Excel.

4) Software Elipse E3, version 4.8.352.

De posse destes materiais e softwares, os alunos, acompanhados de seus professores, puderam dar andamento aos trabalhos de prototipagem 3D computacional, fazer a impressão, montagem da maquete, instrumentação da maquete, programação dos controladores lógicos programáveis e finalmente realizar a construção do sistema de supervisão e controle remoto da maquete. Desta forma, é possível a experimentação de um processo completo de projeto e execução com instalação e testes de funcionamento.

se a planta no modo montagem do Inventor.

$\mathrm{Na}$ construção da planta foram feitas modificações estéticas na área externa da casa, mais especificamente, no jardim e área de lazer.

Em contrapartida, em um primeiro momento, a planta não foi construída levando em consideração os sensores que seriam utilizados no projeto, e sim do maquinário, tal como exposto na Figura 1. 


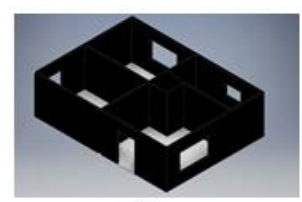

(a)

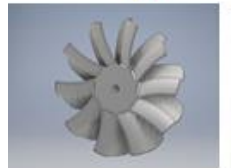

(c)

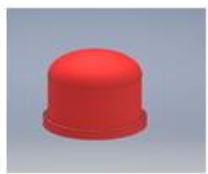

(d)

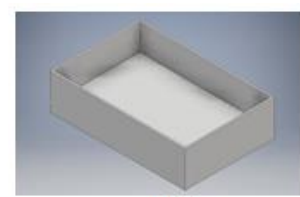

(b)

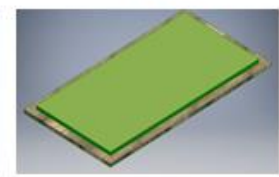

(e)

Figura 1: Estrutura geral da "Smart House". (a) Estrutura da "Smart House" com cômodos, janelas e portas. (b) Base com muros para a "Smart House". (c) Ventoinha que representa o ar-condicionado no maquinário. (d): LED. (e) Jardim para a área de lazer. Fonte: Os autores.

Uma visão geral do projeto concluído da casa, em 3D, pode ser visto na Figura2.

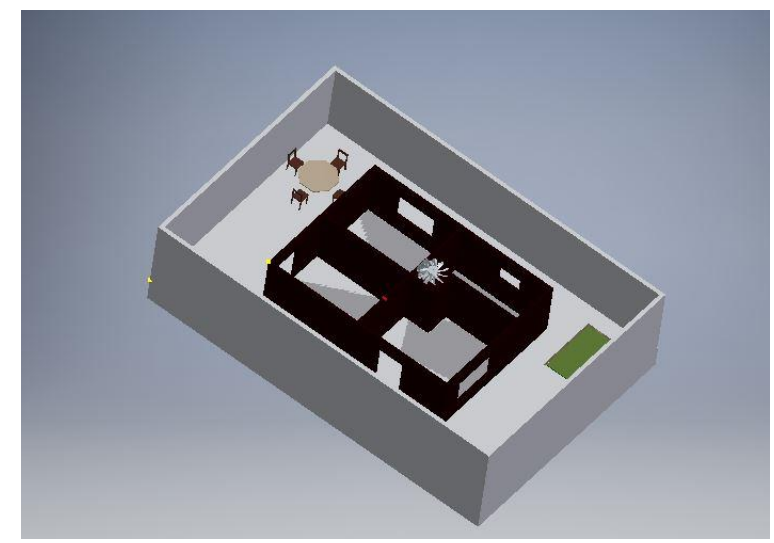

Figura 2: Planta completa. Fonte: Os autores.

Após o projeto realizado com suporte computacional, foi realizada a impressão 3D das peças que permitiram a completa construção da maquete.

\subsection{A montagem e Instrumentação do} Protótipo da Casa Inteligente.

Durante todo o segundo semestre letivo de 2019, na disciplina Fundamentos de Automação efetuou-se a construção e sensoriamento do projeto de forma a buscar os conceitos dispostos na pesquisa de (GHAFFARIANHOSEINI et al., 2013).

$\mathrm{Na}$ sala da maquete foi alocado um sensor fotoelétrico (Figura 3) com ajuste de distância com vistas à detecção da presença de indivíduos no ambiente, sonorizado por meio de um buzzer. 


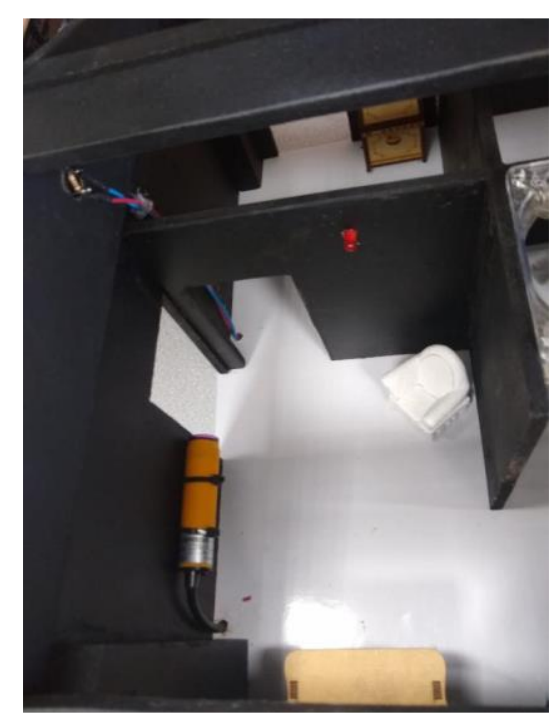

Figura 3: A sala e seu sensoriamento. Fonte: Os autores.

O alarme é desarmado,

manualmente, por um botão, tal como exposto nas Figura 4.

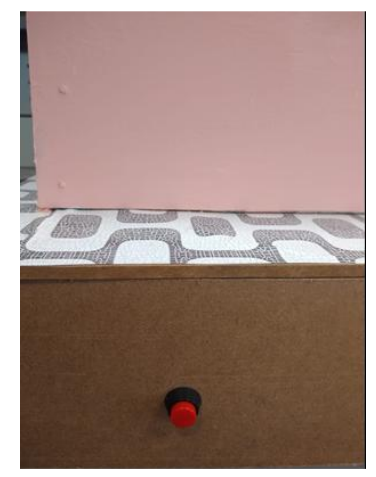

Figura 4: Botão para o desarmar o alarme. Fonte: Os autores.

No banheiro nenhum sensoriamento foi realizado no local, tal como exposto na Figura 5.

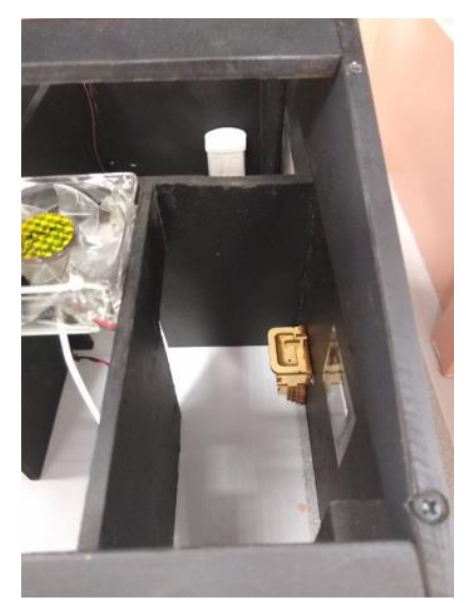


Figura 5: Cômodo com o banheiro da casa. Fonte: Os autores.

No cômodo do quarto alocou-se um cooler para representar a presença de um ar condicionado, associado com um sensor de temperatura LM35 para controle da temperatura do ambiente, como apresentado na Figura 6.

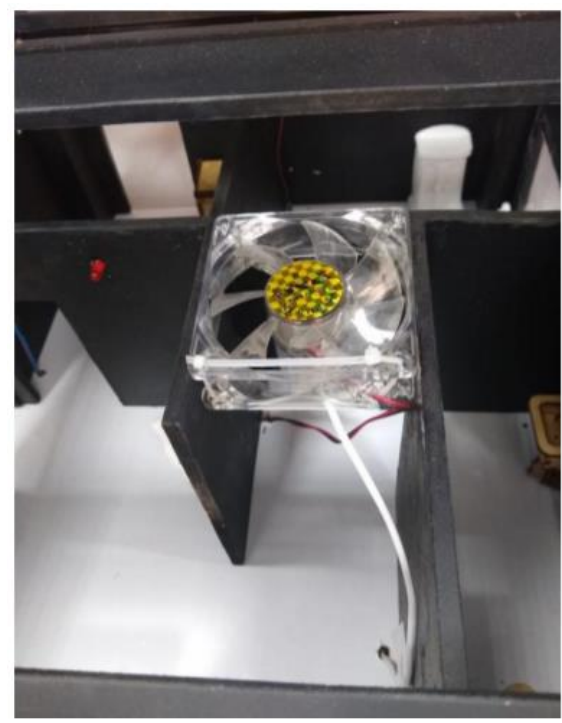

Figura 6: Sensor de temperatura e cooler para resfriamento do ambiente. Fonte: Os autores.

$\mathrm{Na}$ vista frontal da casa acoplou-se um sensor fotoelétrico com ajuste de distância com a finalidade de automatização do portão. O sensor detecta presença a partir de aproximadamente 6 cm de distância da sua base. Desse modo, quando um carro estiver se aproximando do portão, o mesmo abrirá automaticamente (Figura 7).

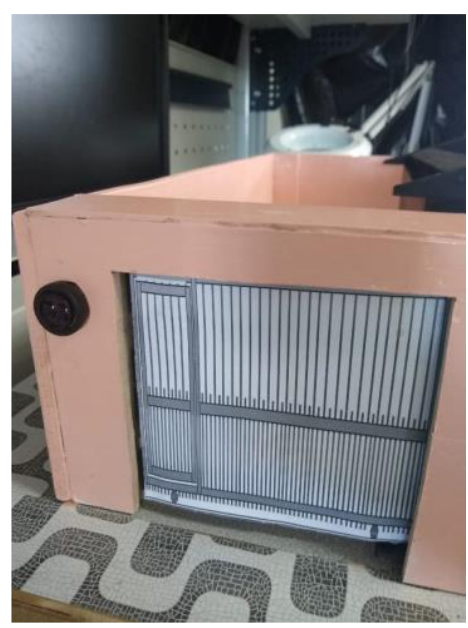

Figura 7: Acionamento do Portão eletrônico. Fonte: Os autores.

De modo a agregar ao projeto um sistema simples de irrigação, um jardim foi construído e as condições ambientais foram aferidas para o acionamento das bombas de irrigação do sistema.

Um sensor de temperatura e umidade THT860 foi colocado para quando o ambiente atingir o setpoint, ou ponto de ajuste, de 27 graus centígrados de temperatura e $25 \%$ de umidade, para o acionamento da bomba de irrigação.

A água é aspergida no jardim por meio de pequenos orifícios inseridos em 
uma mangueira transparente, tal como exposto na Figura 8.

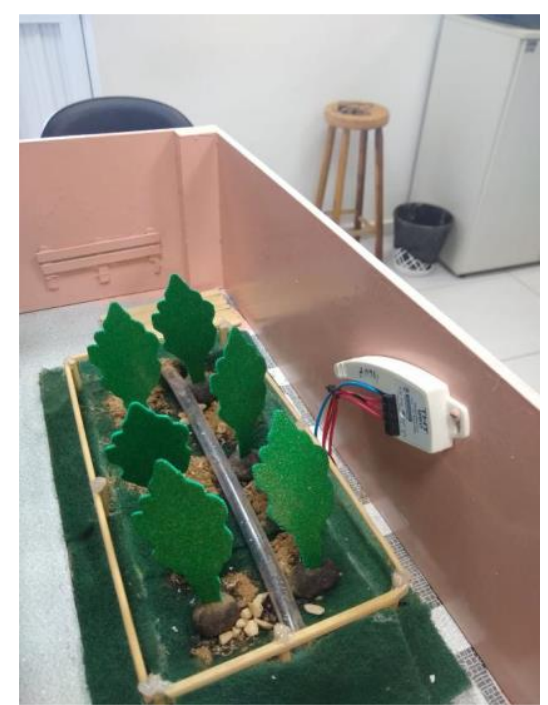

Figura 8: Jardim com sensor de temperatura e umidade. Fonte: Os autores.

Abaixo do maquinário colocou-se um recipiente de plástico para reservar a água para irrigação.
A partir do momento que o THT860 inicia sua função, a água chega ao jardim por intermédio de uma bomba de captação (Figura 9).

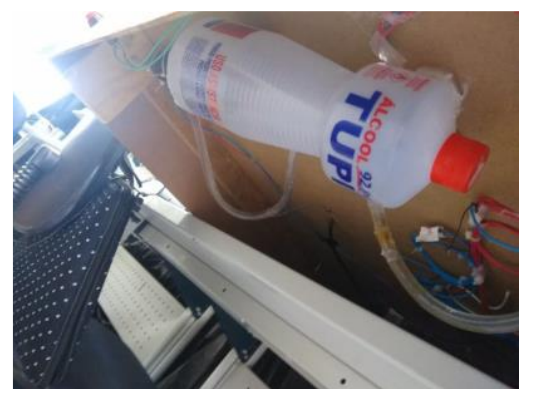

Figura 9: Reutilização da água utilizada na irrigação. Fonte: Os autores.

Para implementar a automação deste projeto, as escolhas dos sensores foram realizadas tendo em vista o custo dos produtos e a necessidade da "Smart House".

Sendo assim, no portão de entrada da casa colocou-se um sensor fotoelétrico com a possibilidade de calibrar uma distância $6 \mathrm{~cm}$ para a abertura do mesmo, programando um tempo de 10 segundos para permanecer aberto e após este tempo, o mesmo é fechado.

Nos muros exteriores foram alocados LED's que representam as luzes externas da casa, onde adequou-se um sensor fotoelétrico para a detecção de presença, com acionamentos concomitantes com o alarme e as luzes internas da casa.

No interior da "Smart House" foram colocados dois sensores, sendo um deles o LM35 responsável por realizar a leitura da temperatura da casa que, ao atingir o valor de 27 graus, liga um cooler que representa, na maquete, um ar condicionado.

Já o outro sensor, localizado na porta da sala da casa, é um sensor fotoelétrico que identifica o movimento ao entrar na residência, representando um alarme de segurança da casa, o qual possui um botão para ser desligado. Entretanto, enquanto este botão não for acionado o 
buzzer que faz assoar o alarme mantem-se ligado.

$\mathrm{Na}$ parte externa do maquinário, especificamente no jardim, foi colocado um sensor THT860 que realiza a leitura da temperatura e da umidade, com vistas ao acionamento de uma bomba que fará a irrigação do jardim. A bomba só é acionada quando os valores medidos forem iguais aos pré-programados de disparo para os limiares de temperatura e umidade relativa do ar.

Todos esses sensores foram programados com o uso do software SPDSW 4.4 e gravados em um Controlador Lógico Programável da HI Tecnologia modelo RION.

\subsection{A programação.}

Para fazer a programação a equipe, tutorada pelos docentes, utilizou os conhecimentos adquiridos sobre a programação em Ladder durante as aulas de fundamentos de automação, assim como buscou conhecimentos complementares para elaboração do seu programa, sendo este implementado no programa SPDSW, adequado ao CLP RION.

No presente projeto, foram utilizados dois controladores lógicos programáveis, por conta da quantidade de sensores do dispositivo.

Estes, receberam os nomes: CLP1 e CLP2. Para o melhor entendimento da programação, foi elaborada uma tabela no software Excel (Tabela 1) com as devidas separações de entrada e saída para cada CLP e qual sensor estava sendo programado.

Tabela 1: Planejamento dos controladores

\begin{tabular}{|c|c|}
\hline CLP 1 & CLP 2 \\
\hline SAIIDAS & SAIIDAS \\
\hline Buzzer $\left(\mathrm{O}_{0}\right)$ & Ponte H Fechar $\left(\mathrm{O}_{0}\right)$ \\
\hline Luz de Alarme $\left(\mathrm{O}_{1}\right)$ & Ponte H Abrir $\left(\mathrm{O}_{1}\right)$ \\
\hline Cooler $\left(\mathrm{O}_{2}\right)$ & Luz Garagem $\left(\mathrm{O}_{2}\right)$ \\
\hline Bomba $\left(\mathrm{O}_{3}\right)$ & \\
\hline ENTRADAS & ENTRADA \\
\hline I0: SENSOR & I0: SENSOR \\
ALRME & PORTÃO \\
\hline I1: BOTÃO & \\
\hline ALARME & \\
\hline CONTANTES & CONTANTES \\
\hline Q0 (REAL) $=50$ & Q2 (REAL) $=26$ \\
\hline Q1 (REAL) $=4095$ & Q4 (REAL) $=27$ \\
\hline Q2 (REAL) $=26$ & Q5 (REAL) $=50$ \\
\hline Q4 (REAL) $=27$ & Q6 (REAL) $=4095$ \\
\hline & Q7 (REAL) $=10$ \\
\hline
\end{tabular}

Fonte: Os autores.

$\mathrm{Na}$ Figura 10 podemos visualizar como foi feita a programação Ladder do Controlador 1 (CLP 1). 


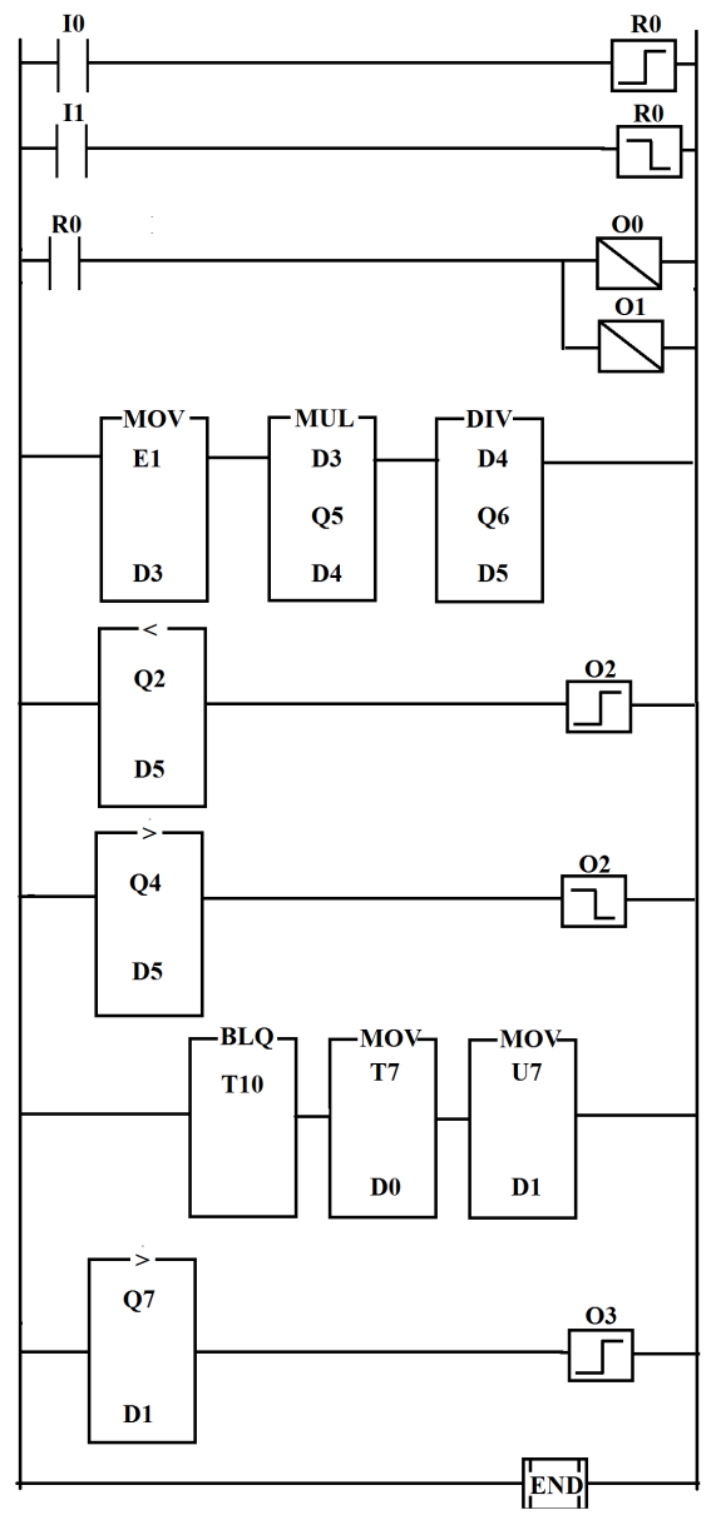

Figura 10: Programação do CLP1. Fonte: Os autores.

Na Figura 11, podemos visualizar como foi feita a programação Ladder do Controlador 2 (CLP 2). 


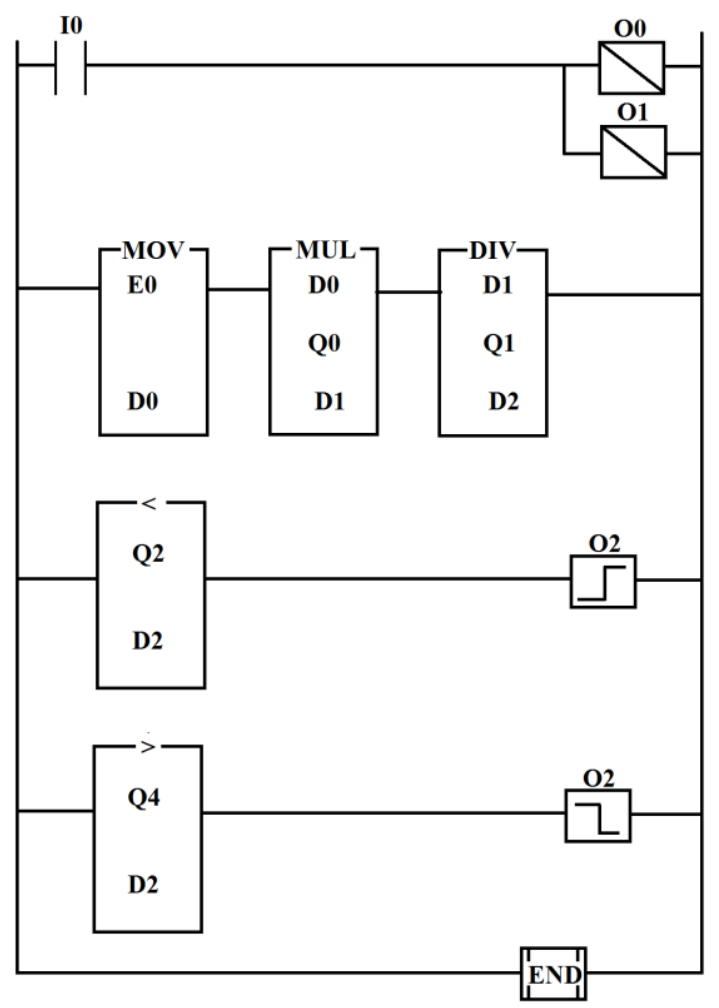

Figura 11: Programação do CLP2. Fonte: Os autores.

\subsection{Supervisório Elipse}

Por meio do Software Elipse E3, version 4.8.352, um sistema supervisório foi desenvolvido para monitorar, controlar e supervisionar as variáveis e dispositivos componentes da "Smart House".

A tela inicial foi elaborada de modo a apresentar o sistema disponibilizar o menu para acesso à tela do processo em si, conforme exibe a Figura 12.

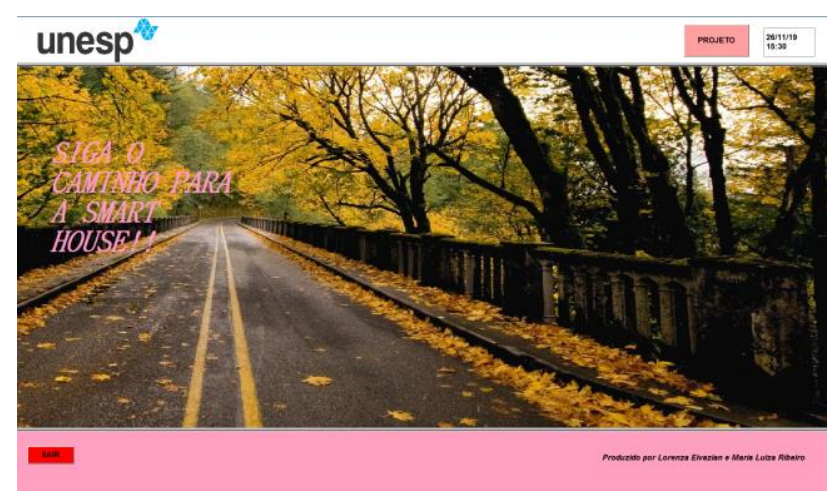

Figura 12: Visão Inicial do Supervisório. Fonte: Os autores.

Na tela 2, carregada logo a seguir da tela de apresentação, observa-se que o sistema supervisiona a casa como um todo, tal como exibe a planta da Figura 13. 


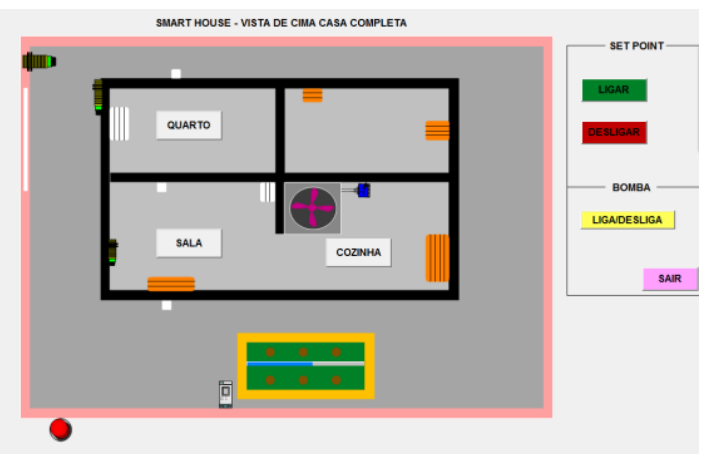

Figura 13: Supervisório com a planta baixa da casa inteira. Fonte: Os autores.

Na tela 3 do sistema de supervisão, o foco está em parte da área externa e na sala de visitas, tal como exibe a Figura 14.

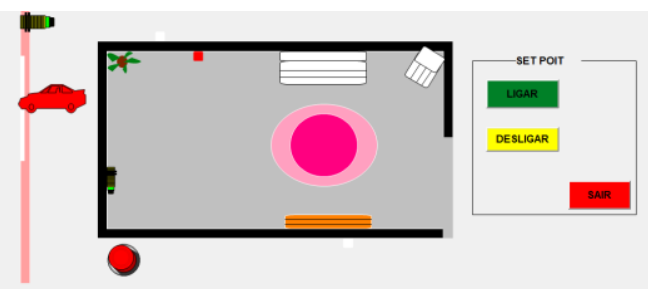

Figura 14: Visão específica da sala e de parte da área externa. Fonte: Os autores.

$\mathrm{Na}$ tela 4 do supervisório, monitora-se o quarto e o sensoriamento do ambiente, tal como exibe a Figura 15.
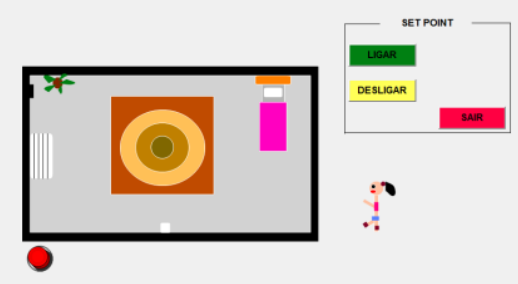

Figura 15: Visão específica do quarto. Fonte: Os autores.

Com isto, verificou-se ser possível trabalhar, na modalidade de tutoria, junto aos discentes, encaminhando um processo de construção desde a concepção e o projeto, perpassando pela modelagem, impressão, construção, instrumentação, programação e desenvolvimento de um completo aplicativo para automação e controle de uma planta, neste caso, uma casa inteligente com suporte de uma impressora 3D como foi descrito no trabalho de Catal e Tekinerdogan (2019), no tocante a aprender tecnologias relevantes, de forma a atuar no diretamente currículo educacional e incluir e refletir sobre as novas tecnologias, conceitos e paradigmas.

A adoção no ensino superior da utilização da impressão 3D durante o aprendizado baseado em projetos, proposta por Ford e Minshalla (2019), motiva os discentes e promove a integração do desenvolvimento de habilidades e enriquece $o$ currículo por meio da 
incorporação nos cursos superiores de engenharia.

No transcorrer de todo este processo, os discentes ganharam confiança e verificaram a correta aplicação dos conceitos desenvolvidos em sala de aulas, entenderam a importância dos conhecimentos interdisciplinares para a

\section{CONCLUSÃO}

Os resultados apontaram para o fato de que tratar o tema de modo inter $\mathrm{e}$ transdisciplinar mostrou-se uma necessidade nos cursos de Engenharia das Universidades, principalmente naquelas em que os objetivos maiores residem na utilização de tecnologias em suas práticas de trabalho e pesquisa.

$\mathrm{O}$ experimento proposto proporcionou aos discentes uma valorização do processo de aprendizagem que acabou por transcender os conhecimentos interdisciplinares inerentes ao próprio

\section{AGRADECIMENTOS}

Os autores agradecem ao $\mathrm{CNPq}$ pelo suporte às pesquisas.

\section{REFERÊNCIAS}

BLIKSTEIN, P. Digital fabrication and "Making" in education: the democratization of invention. J. WalterHerrmann, C. Büching (Eds.), FabLabs Mach. Makers Invent., Transcript Publishers, Bielefeld (2013), pp. 1-21, 10.1080/10749039.2014.939762

CATAL, C.; TEKINERDOGAN, B. Aligning Education for the Life Sciences Domain to Support Digitalization and Industry 4.0. Procedia Computer Science, v.158, p.99-106, 2019.

FORD, S.; MINSHALLA, T. Invited review article: Where and how $3 \mathrm{D}$ printing elaboração completa de um projeto de automatização e trabalharam de maneira a buscar o menor custo como foi indicado por (MARQUES (a), 2017) e foi possível experienciar um completo processo de desenvolvimento de projeto com sua execução, instalação e testes de funcionamento.

curso e justificam as mudanças no currículo.

Disciplinas aliadas a técnicas pedagógicas como as aplicadas nesta pesquisa, fundamentadas na cultura maker, de "pôr a mão na massa", proporcionam também aos discentes um update na preparação deste profissional para a vida.

Atrelado a isso, o fato de empregarmos componentes de automação de uso industrial - e de baixo custo agregam, além de conhecimento, novas perspectivas de trabalho e pesquisas. É a educação nos rumos dos 4.0, isto é, Educação 4.0.

is used in teaching and education. Additive Manufacturing, v.25, p.131-150, 2019.

GHAFFARIANHOSEINI, A. et al. The essence of future smart houses: From embedding ICT to adapting to sustainability principles. Renewable and Sustainable Energy Reviews, v. 24, p. 593607, 2013.

LI, K.; NABRZYSKI, J. Virtual machine placement in cloudlet mesh. Journal of Communications and Networks, v.20, n.3, pp. 266-278, 2018.

MARQUES, F (a). A corrida da Indústria 4.0, Revista FAPESP, 2017. [Online].

Available at: 
https://revistapesquisa.fapesp.br/2017/09/2 2/a-corrida-da-industria-4-0/. [Acessado: 11-jul-2019].

MARQUES, F (b). O Brasil da Internet das Coisas, Revista FAPESP, 2017. [Online]. Available at: https://revistapesquisa.fapesp.br/2017/09/2 1/o-brasil-da-internet-das-coisas/.

[Acessado: 11-jul-2019].

SUNG, W.; HSIAO, S. The application of thermal comfort control based on Smart House System of IoT. Measurement, v.149, p.1-16, DOI 106997, 2020. 